\title{
MALFORMAÇÃO VASCULAR DA MEDULA CÉRVICO-TORÁCICA DIAGNOSTICADA PELA ANGIOGRAFIA DE ARTÉRIA INTERCOSTAL TRATAMENTO CIRÚRGICO
}

\author{
Oscar Fontenelle Filho* \\ Glieb Avila Pereira** \\ Pedro ANGelo ANdreioulo ***
}

O diagnóstico das malformações vasculares da medula dependia, até pouco tempo, da laminectomia exploradora, embora, em alguns casos, a mielografia fornecesse sinais indiretos de sua presença. Entretanto, tal situação vem se modificando, graças, inicialmente, à arteriografia da vertebral e, ulteriormente, à aortografia que permite estudar a vascularização dos demais segmentos da medula. Com o aprimoramento dos métodos angiográficos aumentaram não só o número de casos de malformações vasculares da medula diagnósticados pré-operatòriamente, como também as possibilidades do estudo mais objetivo de sua suplência sangüinea. Em conseqüência, novo problema começa a ser debatido, qual seja o da melhor terapêutica a ser aplicada em tais casos. Embora ainda prevaleça a tendência conservadora, o tratamento cirúrgico, desde a simples ligadura dos pedículos vasculares até as extirpações radicais da malformação, tem sido utilizado com sucesso $6,7,8$.

Nosso propósito é o de relatar um caso de malformação vascular do segmento cervico-torácico da medula, cujo diagnóstico foi confirmado pela arteriografia seletiva de uma das artérias intercostais, sendo tratada cirúrgicamente pela ligadura do pedículo vascular. Acreditamos que, no momento, dada a controvérsia que ainda existe sôbre o melhor tratamento dessas lesões e o pequeno número de pacientes operados, cada caso que possa trazer qualquer subsídio à solução do problema merece divulgação.

\section{O B S E R V A C A O}

J.B.B.F., branco, brasileiro, casado, 28 anos, internado na Clinica são Bento em 16-08-1969. Relatou o paciente que um ano antes começara a sentir dor ao nível da região lombossacra, que se irradiava para o membro inferior esquerdo, desde a nádega até o pé; por recomendação médica permaneceu em repouso durante 15 dias no leito e fêz uso de analgésicos, recuperando-se completamente. Anteriormente já havia sofrido três crises idênticas, porém, menos intensas e de menor duração. Há cinco meses não tem dor, porém começou a notar progressiva dificuldade de movimentar o membro inferior esquerdo. Observou também que a coxa

* Chefe do Serviço de Neurocirurgia do Hospital Estadual Miguel Couto; ** Neurologista do Hospital Estadual Souza Aguiar; *** Radiologista da Clínica Emilio Amorim (Rio de Janeiro, Brasil). 
esquerda ficou mais "fina" que a direita. Há dois meses foi correr e verificou que a perna esquerda "arrastava" (sic). As vêzes tem formigamento na planta do pé esquerdo. No início também sentia discreta dôr ao nível da ponta do omoplata esquerdo com irradiaçāo para o membro superior do mesmo lado, seguindo a face externa do braço e superficie anterior do antebraço. Há 4 meses notou diminuição da potência sexual. Há 10 anos foi acometido de cefaléia intensa, tendo consultado um médico que diagnosticou hipertensão intracraniana; fêz punção lombar na ocasião, porém não sabe o resultado. Em fevereiro de 1962 teve nova crise de cefaléia, mais intensa na nuca e "latejante"; o exame neurológico e as radiografias do crânio foram normais. Segundo relatório do neurologista que o atendeu naquela época e o seguiu até a data atual, o paciente, no inicio de 1968, queixou-se de dôr no membro inferior esquerdo, de distribuiçāo ciática, e impotência coendi, sendo de notar que, 24 horas antes do aparecimento da dor ciática, sentiu forte cefaléia; nessa ocasião o exame neurológico foi normal. Ulteriormente o paciente observou mancha cutânea ao nivel do omoplata esquerdo, onde havia sudorese acentuada, em contraste com as áreas cutâneas normais. Em razão da dor ciática foi consultado um ortopedista que suspeitou de hérnia discal, prescrevendo analgésicos e recomendando repouso. $O$ paciente tem sentido periòdicamente cefaléia, geralmente de aparecimento súbito e que regride espontãneamente ao fim de um periodo médio de uma semana. Nunca ocorreram distúrbios esfincterianos. Exame neurológico - Marcha claudicante, com diminuição de fôrça muscular no membro inferior esquerdo, comprometendo principalmente o extensor do primeiro pododáctilo, dos extensoras do pé, dos flexores da perna e dos psoas. Hipotrofia muscular global no membro inferior esquerdo. Reflexos patelar e aquileu exaltados à esquerda. Clonus do pé e sinal de Babinski à esquerda, Ausência de distúrbios objetivos da sensibilidade. Fundos oculares normais. O exame físico mostrou apenas mancha cutânea de côr "café com leite" na região escapular esquerda. Radiografias do crinio normais. Punção lombar: raquimanometria normal. Exame do líquido cefalorraqueano: $20 \mathrm{mg} / 100 \mathrm{ml}$ de proteínas; com 280 hemácias por $\mathrm{mm}^{3}$, o que foi atribuido a traumatismo da punção. Eletrencefalograma: traçado indicando foco temporal direito. Angiografia pela carótida interna direita e pneumoencefalografia normais. O paciente teve alta hospitalar em 23-8-1969.

Em janeiro de 1970 foi re-examinado, encontrando-se, além das alteraçōes já assinaladas, discreta diminuição da sensibilidade dolorosa e térmica até o nivel de $\mathrm{T}_{2}$; não havia distúrbio da sensibilidade profunda, sendo questionável ligeira diminuição da sensibilidade tátil. Em consequiēncia, foi feita nova punção lombar que forneceu liquido límpido, sendo normal a raquimanometria. Na mesma ocasião fol feita mielografia que forneceu imagem compativel com o diagnóstico de malformação vascular da medula cérvico-torácica. A seguir foi praticada aortografia, com cateterismo seletivo de uma das intercostais que confirmou a existência de malformação vascular (fig. 1).

Intervencão cirúrgica (26-2-1970) - Ampla laminectomia, de C6 a T3. Aberta a dura-mater, a malformação fol totalmente exposta (fig. 2) e seu pediculo arterial, já visualizado na angiografia, identificado e clipado por via intradural. Logo a seguir à clipagem do pediculo, houve acentuada redução da malformação (fig. 2). o pós-operatório imediato transcorreu sem novidades, a não ser pela persistência de pequena fístula de líquido cefalorraqueano que obrigou a reintervenção, com resseccão do seu trajeto.

O paciente teve alta, sem qualquer modificação em seu estado neurológico. Foi revisto para contrôle em 18-5-70 e 13-10-70, queixando-se de fasciculaçōes ao nivel do omoplata esquerdo e da nádega e eventuais sensaçōes de dôr, como choque elétrico, no membro inferior esquerdo. Os exames nessas duas ocasiões foram semelhantes e mostraram: discreta claudicação na marcha, em razão de ligeiro déficit motor no membro inferior esquerdo, de predominância distal. Atrofia muscular no membro inferior esquerdo, com uma diferença de $5 \mathrm{~cm}$ na coxa e $3 \mathrm{~cm}$ na perna, em relação ao membro inferior direito. Reflexos profundos ainda exaltados no membro inferior esquerdo, porém menos vivos do que nos exames anteriores $e$ sem clonus do pé, antes registrado. Reflexo cutâneo-plantar em extensão à esquer- 
da e em flexão à direita. Reflexo cremasterino diminuido à esquerda. Discreta diminuiçāo das sensibilidades dolorosa e térmica até o nivel de T9-T10. Sensibilidades táctil e profunda normais. O paciente encontrava-se mais confiante e reveIou que sua potencia sexual havia retornado. Em dezembro de 1970 recebemos notícias dadas pelo próprio doente, que informava encontrar-se perfeitamente bem. Não tivemos oportunidade de examiná-lo, visto que encontrava-se no interior do Pais, trabalhando normalmente.
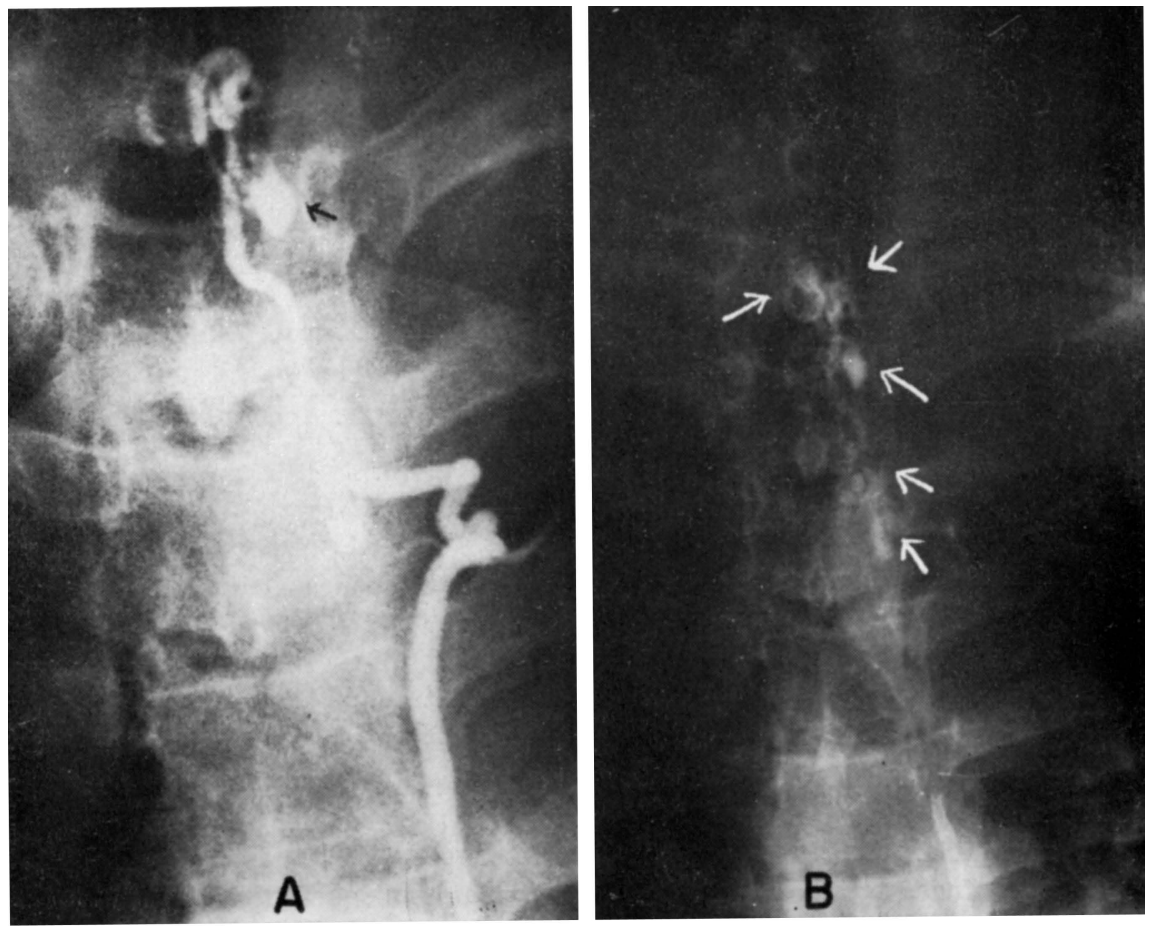

Fig. 1 - Caso J.B.B.F. $\quad$ À esquerda, angiografia seletiva da intercostal mostrando a malformação vascular da medula cervico-torácica e seu pediculo arterial; á direita, aneurisma sacular na superfície da medula.

\section{$\mathrm{C} O \mathrm{O}$ E N T $\mathrm{A}$ R I O S}

A evolução do caso é bastante interessante e instrutiva, pois a suspeita de malformação vascular da medula como causa dos possíveis episódios de hemorragia sub-aracnoidéia só foi viável depois que o paciente começou a apresentar sinais de comprometimento medular. A mielografia e a seguir, a arteriografia seletiva de uma das intercostais evidenciaram a malformação vascular envolvendo o segmento cervico-torácico da medula. Mediante intervenção cirúrgica foi possível expor e ligar o pediculo vascular aferente da malformação por via intradural, com imediata redução da anomalia. A 

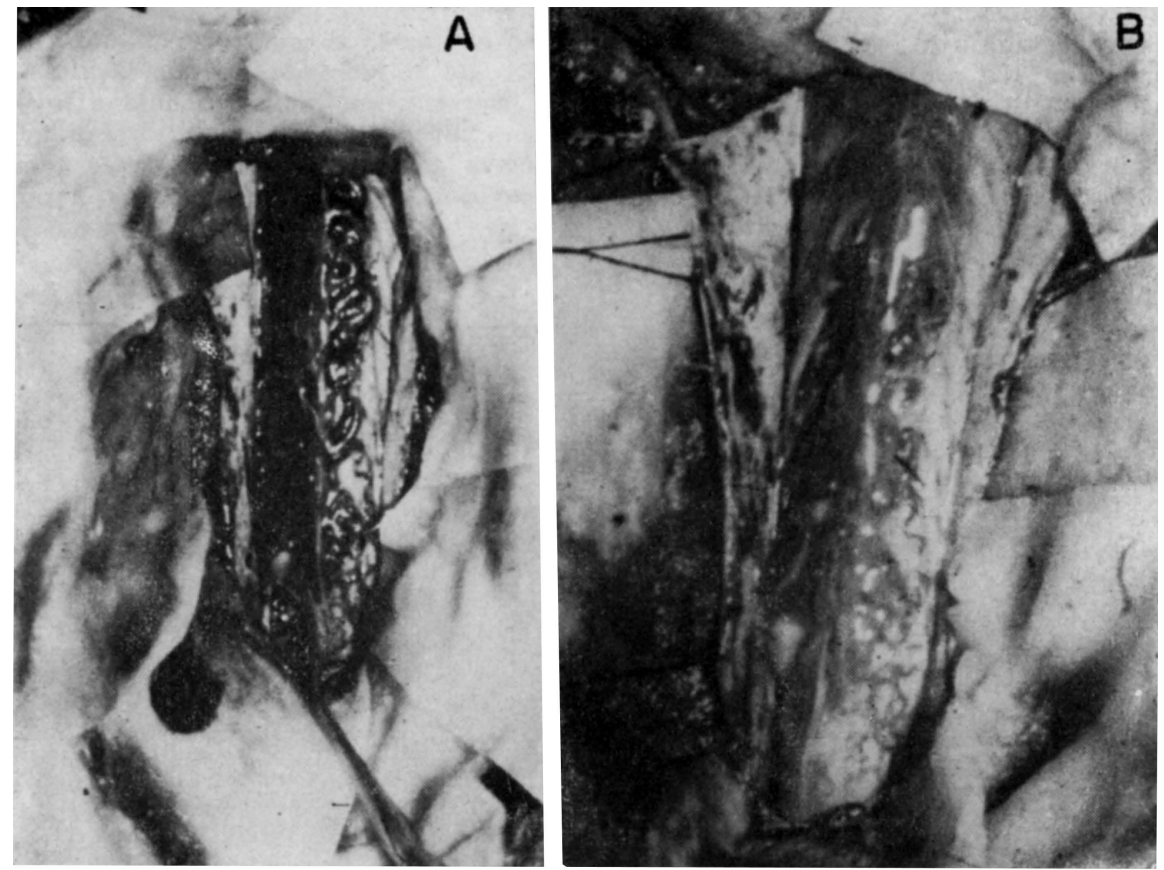

Fig. 2 - Caso J.B.B.F. À esquerda, aspecto da malformação durante o ato operatório; à direita, aspecto depois da ligadura do pedículo arterial da malformação.

eficácia de ligadura parece confirmada pela evolução pós-operatória favorável, sendo o paciente seguido durante um ano, apesar de não ter sido confirmado por nova angiografia.

A nomenclatura histológica das malformações vasculares da medula é bastante confusa, talvez devido à falta de maiores oportunidades para estudos microscópicos. E possível que, persistindo a tendência atual para as extirpações cirúrgicas em substituição aos métodos conservadores, os anátomo-patologistas venham a ter o ensejo de estudar mais detida e completamente maior número de casos e, com isso, esclarecer melhor sua natureza morfológica. Para tanto, muito tem contribuído o aprimoramento dos métodos angiográficos $1,2,3,6,7,8$ o que tornou viável a confirmação diagnóstica pré-operatória da maioria dos casos. A freqüência das anomalias vasculares da medula aumentará à medida que a angiografia espinhal fôr utilizada com maior assiduidade, como aconteceu em relação às malformações arterio-venosas cerebrais, com o uso da angiografia cerebral. Como estas últimas, as anomalias vasculares da medula parecem ser nada mais do que aneurismas artério-venosos ${ }^{6}$, cuja principal característica é a existência de comunicaçōes artério-venosas, sem a presença da rêde capilar intermediária. Isto pode ser verificado pelo estudo das diversas fases angiográficas, observandose a opacificação sucessiva dos pedículos arteriais que suprem a malforma- 
ção, a massa de vasos anômalos, composta de fístulas artério-venosas, e as veias que drenam a malformação. As artérias que contribuem para a vascularização dessas malformações vêm de um ou mais pediculos e podem ser uni ou bi-laterais. Apesar de seu aspecto e tamanho anômalos, tais artérias têm topografia normal, isto é, suas origens, cursos e pontos de penetração no canal raqueano são os habituais ${ }^{6}$. Com relação às veias de drenagem é necessário destacar, como acentuam Houdart, Djindjain e Hurth ${ }^{6}$, fato de grande importância prática, qual seja o de que tais veias podem se estender à distância, para cima ou para baixo, da fístula arteriovenosa. Isto explica porque algumas malformações parecem se alongar por tôda a extensão da medula, dando a impressão de serem muito maiores do que na realidade o são. Tais dilatações venosas são capazes de provocar síndromes de compressão medular à distância da verdadeira malformação e a mielografia revelar, a êste nivel, bloqueio completo, simulando tumor ${ }^{6}$.

No que concerne a sua localização, as malformações artério-venosas predominam nitidamente na superfície posterior da medula, o que é favorável ao acesso cirúrgico. Também tem sido assinalada sua maior freqüência na medula torácica e lombossacra (Krayenbuhl e col. ${ }^{7}$ ). Dos 17 casos relatados por Krayenbuhl, Yasargil e McClintock ${ }^{7}$, em sòmente um estava a lesão confinada à medula cervical. Houdart, Djindjain e Hurth ${ }^{6}$ observaram, em seus casos, certa constância entre o tamanho e o número de pedículos vasculares em relação à localização da malformação. Assim, êles assinalaram que as anomalias vasculares cervicais são habitualmente menores que as torácicas, porém elas possuem artérias aferentes numerosas e bilaterais, enquanto que as dorsais, embora mais volumosas, possuem menor número de artérias aferentes, comumente unilaterais. As malformações dorsolombares são, em geral, de pequeno tamanho e supridas, aparentemente, por um único pedículo arterial. O pequeno tamanho da malformação nesta última região explica a dificuldade de demonstrá-la e a necessidade de técnica angiográfica mais apurada ${ }^{1,2,3}$.

Antes da angiografia espinhal a confirmação diagnóstica de uma malformação vascular da medula constituia dificil problema. As radiografias da coluna vertebral excepcionalmente demonstram qualquer alteração que, quando existe, não apresenta qualquer especificidade. Elas podem revelar, principalmente nos pacientes mais jovens e nas lesões volumosas, alargamento do canal vertebral, erosões dos pedículos vertebrais e, mais raramente ainda, calcificações. Têm sido assinaladas escolioses ${ }^{2}$ e é possivel esperar, em casos excepcionais, dilatação do buraco intervertebral ou do forame transversário na coluna cervical ${ }^{2}$. As imagens mielográficas, tidas como típicas, formadas por defeitos lineares e serpentiginosos na coluna de contraste, não são constantes nem patognomônicas ${ }^{2}$ pois elas podem ser observadas nos tumores medulares. Se a mielografia demonstra bloqueio e existe dúvida sôbre o diagnóstico de tumor medular, é recomendável introduzir contraste no segmento oposto do canal vertebral, a fim de delimitar a extensão do bloqueio. Ocasionalmente tal medida pode revelar a presença de uma malformação vascular. $\mathrm{E}$ muito raro existir bloqueio raquimanométrico, porém a taxa de proteínas do liquido cefalorraqueano está freqüentemente elevada. 
É importante proceder-se à mielografia com o paciente em decúbito dorsal, pois do contrário a malformação poderia passar despercebida, dada a freqüência de sua localização na fase posterior da medula.

A arteriografia espinhal veio, não só facilitar o diagnóstico de tais malformações, como também facilitar a visualização de seus pedículos vasculares e, com isso, estimular as tentativas cirúrgicas. Várias têm sido as técnicas angiográficas usadas: cateterismo femural retrógrado, cateterismo da axilar ou da braquial e angiografia da vertebral. Tem surgido alguma divergência quanto à preferência no uso da aortografia e da arteriografia seletiva das intercostais. Baker, Love e Layton $^{1}$ são de opinião que a angiografia seletiva de uma ou várias intercostais aumenta a possibilidade de passar despercebido outros pedículos arteriais. Di Chiro, Doppnan e Ommaya ${ }^{2}$, ao contrário, preferem o cateterismo seletivo à aortografia. Apesar do inconveniente apontado por Baker e col. ${ }^{1}$, parece-nos que pela angiografia seletiva obtém-se melhores imagens, não só pela maior concentração de contraste na artéria que contribui para a malformação, como também pela ausência da imagem da aorta, que sobrepõe-se à lesão. Na angiografia seletiva, a necessidade do emprêgo da subtração não é tão importante como na aortografia. Di Chiro e col. ${ }^{2}$ nunca observaram espasmos nos membros inferiores com a injeção seletiva das artérias segmentares, mesmo quando a opacificação da malformação era muito mais intensa do que após aortografia. Esta ausência de irritação da medula com a angiografia seletiva sugere que o contraste injetado e que ganha a malformação, não atinge a vascularização normal da medula. Tal fato pode constituir mais uma evidência de que a suplência sangüinea da medula é distinta e separada daquela da malformação. Esses autores ${ }^{2}$ são de opinião que mesmo as malformações vasculares da medula cervical, que podem ser demonstradas pela arteriografia por punção direta da vertebral, são melhor estudadas pela aortografia.

Tem sido assinalada a concomitância de anomalias vasculares medulares com malformações arteriovenosas em outras regiōes (cerebral, hepática, renais, pulmonares e tegumentos cutâneos) ${ }^{2}$.

E grande a diversidade de sintomas e sinais nas anomalias vasculares da medula $5,7,8,9,10,11$, o que explica a dificuldade do diagnóstico pré-operatório. Entretanto, a evolução clínica dos casos geralmente segue um dos seguintes padrões ${ }^{7}:$ 1) progressão vagarosa dos sintomas e sinais; 2) evolução progressiva com periodos estacionários ou de melhora; 3) início apoplético. E comum haver aumento das proteinas liquóricas, podendo também, mais raramente, existir ligeiro acréscimo no número de células; em geral não há bloqueio raquimanométrico, exceto nas malformações volumosas.

Até bem pouco tempo o tratamento cirúrgico das anomalias vasculares da medula era constituído pela laminectomia descompressiva e ou pela radioterapia profunda, ambas reconhecidamente de pouco ou nenhum valor. Teng e Shapiro ${ }^{12}$ recomendam a secção dos ligamentos denteados, baseados nos resultados de seus seis casos. Teòricamente, o tratamento ideal de tais anomalias vasculares será aquêle que, direta ou indiretamente, sejaz capaz de interromper as comunicações artério-venosas, sem interferir com a vas- 
cularização normal da medula, o que só é possivel pelas extirpações totais das malformações ou pelas ligaduras de seus pedículos. O grande receio em tais intervençōes cirúrgicas é que elas possam interferir com a irrigação sangüinea da medula. Entretanto, gradativamente, vem se acumulando observações de pacientes submetidos aos citados tratamentos cirúrgicos, sem que ocorra agravamento pós-operatório da sintomatologia 6, 7,8. Este fato vem reforçar a assertiva de $\mathrm{Kunc}^{8}$ de que as malformações vasculares da medula não possuem conecções com o sistema vascular intramedular; em todos os casos referidos por êste autor foi possivel "distinguir fina rêde pial separando a malformação da medula. Embriològicamente pode-se também supor que as artérias da malformação sejam, em realidade, formadas pela persistência de artérias segmentares supranumerárias ${ }^{8}$.

A extirpação cirúrgica total de malformação é o tratamento ideal, pois com ela estaria eliminada a possibilidade de recidiva, o que sempre é uma eventualidade nos casos de ligadura de um ou mais pedículos vasculares. Entretanto, a ablação total só é possível nos casos em quee as malformações vasculares sejam exclusivamente posteriores e extramedulares. A microcirurgia e o uso de eletrocoagulador bipolar têm contribuido de forma efetiva para as remoções cirúrgicas de tais anomalias. Não obstante, a ligadura de pedículos vasculares ainda constitui para alguns ${ }^{6}$, o método de escolha, tendo sido propostos dois tipos de procedimentos cirúrgicos ${ }^{6}$. Um dêles seria a ligadura do pedículo arterial antes de sua penetração na coluna vertebral, isto é, ao nivel dos troncos arteriais de origem. Tal cirurgia, entretanto, só seria prática com relação às artérias costais, que são de fácil exposição e fàcilmente ligáveis. Acresce que a ligadura feita longe da malformação predispõe para a revascularização, o que constitui um inconveniente, embora ofereça menor risco de isquemia medular. O segundo método consiste na ligadura dos pedículos arteriais junto à malformação, o que requer laminectomia e identificação das artérias que deverão ser ligadas. Isto nem sempre é fácil. Segundo Houdart, Djinjain e Hurth ${ }^{6}$, os pedículos arteriais são mais accessiveis no espaço extra-dural, principalmente na coluna torácica. $\mathrm{Na}$ coluna cervical, onde o canal vertebral é mais largo e as malformaçōes, em geral, de tamanho moderado, a via de acesso intradural é mais prática. Este foi o procedimento cirúrgico que utilizamos em nosso paciente e que nos permitiu clipar o pedículo arterial. Os melhores resultados das extirpações cirúrgicas ou da ligadura dos pedículos vasculares das malformações vasculares da medula têm sido obtidos naqueles pacientes com pouca ou nenhuma manifestação neurológica pré-operatória. Pelo contrário, nos pacientes com acentuados déficits neurológicos pouco ou nada se deve esperar da cirurgia.

S U M M A R Y

Cervico-thoracic vascular malformation of the spinal cord diagnosed by selective arteriography: surgical treatment. A case report.

A case of vascular malformation on the cervico-thoracic level of spinal cord localized by selective spinal angiography is reported. The patient was 
treated surgically by ligadure of the "feeder" vessel. Following surgery the patient gradually improved and ten months later returned to his full activity. The diagnostic and surgical importance of spinal angiography and its contribution to the morphological study of the spinal cord vascular malformations is enphasized. Spinal angiography gives the most accurate information as to the size and extent of the malformation and also the precise location of the "feeder" vessels. Direct operation upon the spinal cord with removal or oblitations of vessels or ligadure of the feeder vessels are the best procedures. The advantages and limitations of both surgical methods are discussed. Total excision is best done under the operating microscope, being essential the use of the bipolar coagulator. The authors feel that the surgical results will be more impressive when spinal angiography will be easily available as to permit earlier diagnosis and surgery before the development of important neurological deficits.

1. BAKER Jr., H. L.; LOVES, J. G. \& LAYTON, D. D. - Angiographic and surgical aspects of spinal cord vascularization. Radiology 88:1078, 1967.

2. DI CHIRO, C.; COPPMAN, J. \& OMMAYA, A. K. - Selective arteriography of arteriovenous aneurysms of spinal cord. Radiology 88:1065, 1967.

3. DOPPMAN, J. \& DI CHIRO, G. - Subtraction angiography of spinal cord vascular malformations. Report of a case. J. Neurosurg. 23:440, 1965.

4. GUIDETTI, B. \& FORTUNA, A. - Surgical treatment of intramedullary hemangioblastoma of the spinal cord. Report of six cases. J. Neurosurg. 27: 530, 1967.

5. HOOK, O. \& LIDVALL, H. - Arteriovenous aneurysms of the spinal cord. A report of two cases investigated by vertebral angiography. J. Neurosurg. $15: 84,1958$.

6. HOUDART, R.; DJINDJAIN, R. \& HURTH, M. - Vascular malformations of the spinal cord: the anatomic and therapeutic significance of arteriography. J. Neurosurg. 26:583, 1966.

7. KRAYENBUHL, H.; YASARGIL, M. G. \& Mc CLINTOCK, H. C. - Treatment of spinal cord vascular malformations by surgical excision. J. Neurosurg. 30: 427, 1969.

8. KUNC, Z. \& BRET, J. - Diagnosis and treatment of vascular malformations of the spinal cord. J. Neurosurg. 30:435, 1969.

9. MOYES, P. D. - Intracranial and intraspinal vascular anomalies in children. J. Neurosurg. 31:271, 1969.

10. ODOM, G. L.; WOODHALL, B. \& MARGOLIS, G. - Spontaneous hematomyelia and angiomas of the spinal cord. J. Neurosurg. 14:192, 1957.

11. TAYLOR, J. R. \& VAN ALLEN, M. M. - Vascular malformation of the cord with transient ischemic attacks. A case report. J. Neurosurg. 31-576, 1969.

12. TENG, P. \& SHAPIRO, M. J. - Arterial anomalies of the spinal cord. Arch. Neurol. Psychiat. (Chicago) 80:577, 1958.

Hospital Estadual Miguel Couto - Serviço de Neurocirurgia - Rua Mario Ribeiro $8 / n .^{\circ}-$ Rio de Janeiro, $G B-$ Brasil. 